\title{
Arte \& Psicose: A Obra de Arthur Bispo do Rosário
}

Art \& Psychosis: The Work of Arthur Bispo do Rosário

Arte y Psicosis: La Obra de Arthur Bispo do Rosário

Maria Cristina Poli \&

Dalva Botelho Gandra

Mesquita

Universidade Federal do

Rio de Janeiro

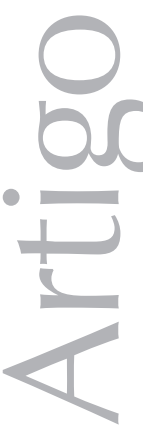

http://dx.doi.org/10.1590 / $1982-3703001382013$

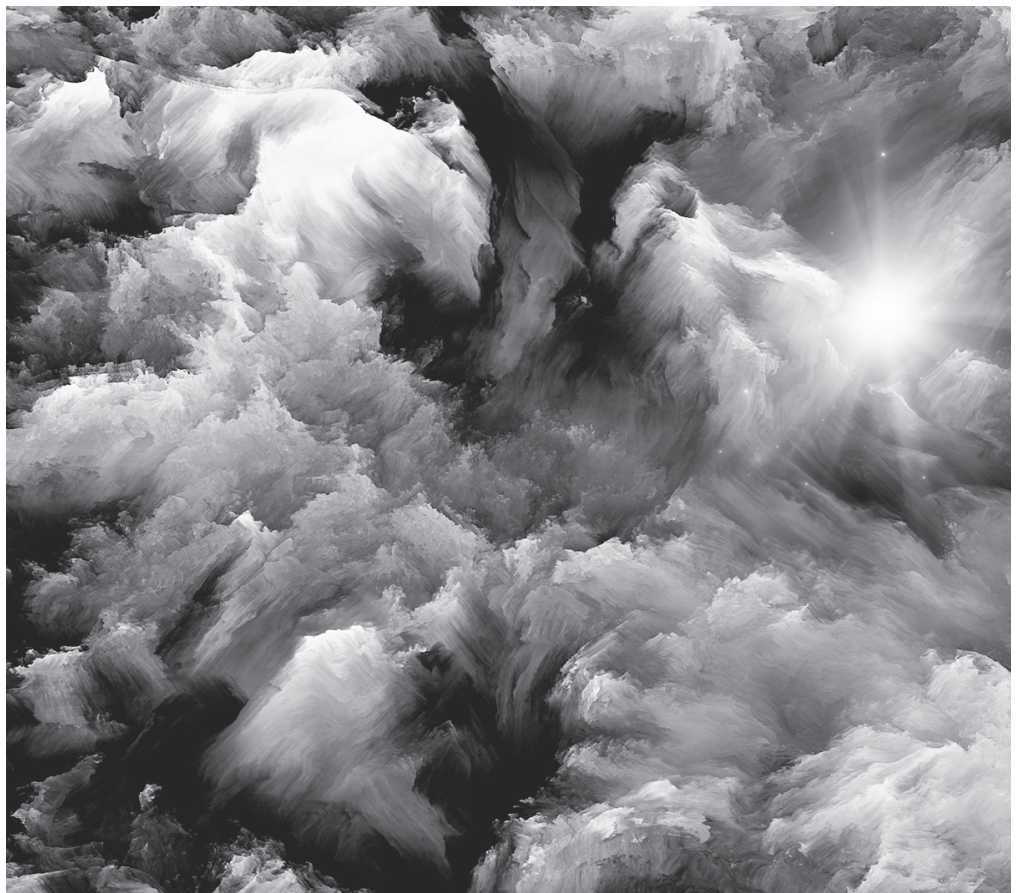


* Estudo desenvolvido com apoio financeiro da Faperj (bolsa de Auxílio Instalação e bolsa de Iniciação Científica) e CNPq (bolsa $\mathrm{PIBIC}$ - Iniciação Científica).

Resumo: Este trabalho se propõe a analisar o enlace entre clínica e pesquisa no campo da Psicanálise e suas consequências na leitura do sujeito do inconsciente. Partimos, pois, da constatação de que, além dos casos clínicos, Freud também se valeu do estudo de artistas e de produções culturais. Em especial, no estudo da psicose, a contribuição precursora de Freud se deu a partir da leitura das Memórias publicadas por Schreber. Foi pela leitura e análise desse livro que o psicanalista baseou suas principais teses acerca da paranoia. Neste artigo, destacamos sua proposição de que o delírio é uma tentativa de reconstrução do mundo, abalado pela crise psicótica. A partir dessa leitura de Freud, buscamos analisar como, de modo similar, a obra de um louco genial, Arthur Bispo do Rosário, demonstra a atualidade do método freudiano e a importância de apreender a psicose, especificamente, nesse enlace com a produção cultural.

Palavras-chave: Psicanálise. Psicose. Arte, Bispo do Rosário. Paranoia (Psicose).

Abstract: This work intends to analyze the link between clinical and research in the field of psychoanalysis and its aftermath in reading the subject of the unconscious. Therefore we started at the realization that, in addition to clinical cases, Freud also used the study of artists and cultural productions. In particular, in studying psychosis, Freud's precursor contribution came from reading the published Memoirs of Schreber. It was by reading and analysing this book that the psychoanalyst based his main theses about paranoia. In this article, we highlight his proposition that delusion is an attempt to rebuild the world, shaken by the psychotic break. From this reading of Freud, we seek to examine how, in a similar way, the work of a mad genius, Arthur Bispo do Rosário, demonstrates the actuality of Freudian method and the importance of apprehending psychosis, specifically, this link with cultural production.

Keywords: Psychoanalysis. Psychosis. Art, Bishop of Rosario. Paranoia(Psychosis).

Resumen: Este trabajo se propone analizar el enlace entre clínica y pesquisa en el campo del Psicoanálisis y sus consecuencias en la lectura del sujeto del inconsciente. Partimos, pues, de la constatación de que además de los casos clínicos, Freud también se valió del estudio de artistas y de producciones culturales. En especial, en el estudio de la psicosis, la contribución precursora de Freud se dio a partir de la lectura de las Memorias publicadas por Schreber. Fue por la lectura y análisis de ese libro que el psicoanalista basó sus principales tesis acerca de la paranoia. En este artículo, destacamos su proposición de que el delirio es una tentativa de reconstrucción del mundo, sacudido por la crisis psicótica. A partir de esa lectura de Freud, buscamos analizar cómo, de modo similar, la obra de un loco genial, Arthur Bispo do Rosário, demuestra la actualidad del método freudiano y la importancia de aprender la psicosis, específicamente, en ese enlace con la producción cultural.

Palabras clave: Psicoanálisis. Psicosis. Arte, Bispo do Rosário. Paranoia (Psicosis).

Este trabalho de pesquisa se propõe a analisar o enlace entre clínica e pesquisa no campo da Psicanálise e suas consequências na leitura do sujeito do inconsciente. Para tanto, partimos da constatação da importância da escrita do caso na obra de Freud (Chiantaretto 1999; Porge, 2007). É essa escrita e o modo como ela opera com o singular do sujeito, rompendo uma tradição médica do estudo de caso pautado na anamnese, que lhe permite fundar a teoria psicanalítica. Uma teoria que, justamente, permite indicar o ponto de enlace estrutural entre esse singular e aquilo que é compartilhado em um determinado laço discursivo. É a partir desse encontro que as categorias nosográficas - as neuroses, psicoses e perversão - atinentes à clínica psicanalítica advêm. 
Em suas escritas de caso, porém, Freud não referia apenas aos pacientes atendidos por ele. Também a análise e interpretação de obras de arte e de personagens como Leonardo da Vinci foram fundamentais. Em especial, o caso de psicose ao qual dedicou um importante estudo - o caso Schreber - nunca foi atendido por Freud. Sua análise do caso se deu a partir das Memórias publicadas por Schreber. Foi pela leitura e análise desse livro que o psicanalista baseou suas principais teses acerca da psicose paranoide.

Depois dele, outros estudos clínicos se seguiram, confirmando algumas e refutando outras das observações do psicanalista. Pode-se, no entanto, reconhecer um trabalho original por parte de Freud na escrita desse caso. Sobretudo, gostaríamos de destacar, sua proposição de que o delírio é uma tentativa de reconstrução do mundo, abalado pela crise psicótica. Ou seja, o psicanalista salienta, por meio de Schreber, a função positiva que seu escrito opera no seu restabelecimento, mesmo que não tenha impedido outras recaídas.

Neste artigo, iremos nos deter, portanto, a esse aspecto da pesquisa, buscando demonstrar como, de modo similar, a obra de um louco genial, Arthur Bispo do Rosário, demonstra a atualidade do método freudiano e a importância de apreender a psicose, especificamente, no enlace com a produção cultural.

\section{Do delírio às Memórias de Schreber: uma reconstrução}

Daniel Paul Schreber nasceu em 1842 e veio a falecer em 1911. Provinha de uma família de burgueses protestantes, abastados e cultos, que já no século XVIII buscavam a celebridade por meio do trabalho intelectual. Muitos de seus antepassados deixaram obra escrita. Os livros de seu bisavô tinham por lema a frase "Escrevemos para a posteridade". Seu pai, Daniel Gottlieb Moritz Schreber, era médico ortopedista e pedagogo, autor de livros sobre ginástica, higiene e educação das crianças.
A carreira de Schreber como jurista, funcionário do Ministério da Justiça do Reino da Saxônia, evoluía regularmente, com promoções sucessivas obtidas por nomeação direta ou eleição interna. Seu primeiro cargo foi o de escrivão adjunto, passando a auditor da Corte de Apelação, assessor do Tribunal e conselheiro da Corte de Apelação. Em 1884, torna-se vice-presidente do Tribunal Regional de Chemnitz. Sua ambição provavelmente requeria algo mais, pois, no dia 28 de outubro de 1884, concorreu às eleições parlamentar pelo Partido Nacional Liberal. Nesta, sofreu uma fragorosa derrota. Tinha 42 anos, estava casado há seis e tinha dezenove anos de carreira jurídica. Em um jornal da Saxônia saiu, nesta ocasião, um artigo irônico sobre sua derrota eleitoral, intitulado: "Quem conhece esse tal Dr. Schreber?". Para quem fora criado no culto orgulhoso dos méritos dos antepassados e fora testemunha da celebridade do pai, esse artigo trazia impressa, como um insulto, a face pública do seu anonimato. O relato autobiográfico de Daniel Paul Schreber se tornou um dos recursos mais utilizados para o estudo da psicose, visto que, ali, seus delírios são descritos de forma muito detalhada.

Freud, a partir da análise do relato autobiográfico de Schreber, postula que a paranoia expressaria um mecanismo de defesa do sujeito contra sua libido homossexual. Ele também estabeleceu a projeção como mecanismo característico da paranoia e sustentou que na redação das Memórias de um doente de nervos observa-se a construção do delírio. Sua tese se fundamenta no seu próprio modelo teórico para as psiconeuroses, baseado nos conceitos de fixação, recalque e retorno do recalcado na forma de sintomas.

O recurso à escrita por parte de Schreber inicia após o período que ele descreve como a morte do sujeito. O início da elaboração das Memórias e a retomada do investimento no mundo são relatados pelo próprio do seguinte modo: 
1 "A formação delirante, que presumimos ser o produto patológico, é na realidade, uma tentativa de restabelecimento, um processo de reconstrução. Tal Reconstrução após a catástrofe é bem sucedida em maior ou menor grau, mas nunca inteiramente; nas palavras de Schreber, houve uma profunda mudança interna no mundo" (Freud, 1996, p. 78).
Ao querer tentar dar ainda neste capítulo outros pormenores relativos à época que há pouco chamei de meu período sagrado, estou bem ciente das dificuldades que se me antepõem (...) remeto-me exclusivamente à memória, uma vez que naquele período eu não estava em condições de fazer qualquer anotação (...) Eu acreditava que a humanidade inteira tinha desaparecido, não havendo, portanto, nenhum, sentido visível em fazer anotações escritas. (Schreber, 1995, p. 74)

É assim que o autor, na sua reconstrução do mundo, empenha-se em um trabalho árduo da escrita. Esse trabalho tem início em 1896, com notas em pedaços de papel, ganhando o formato de relatos em um diário em 1897. Torna-se, posteriormente, um conjunto de rascunhos para as futuras Memórias, reunido em um caderno intitulado Minha Vida. Conforme escreve Oliveira (2010, p. 166): “a elaboração minuciosamente ao longo de todos esses anos, tem para Schreber um papel capital na sua luta para não se reduzir à posição de objeto do gozo divino".

A escrita torna-se, para Schreber, um instrumento do qual ele pode se valer perante os fenômenos alucinatórios que se impõem de forma invasiva. Ele fala, com propriedade, na argumentação sustentada para reaver seus direitos civis: "diante da expressão escrita do pensamento todos os milagres se revelam imponentes (...) e as tentativas de distrair meu pensamento são facilmente superáveis quando posso me expressar por escrito" (Schreber, 1995, p. 312).

Ao longo da elaboração das Memórias, portanto, as alucinações são reduzidas. Ao ocupar a posição do narrador de experiências muito particulares, Schreber promove o encadeamento significante do que se encontra "solto" na forma de alucinação. Conforme seu testemunho:

As Conversas das vozes mudam continuamente e até mesmo nesse período relativamente curto em que me ocupo da realização desse trabalho, elas já sofreram diversas modificações. Já não se ouve muita das expressões que antigamente eram habituais (...) de modo que falar das vozes, em grande parte pode ser definido como um simples zumbido na minha cabeça. (Schreber, 1995, pp. 210-211)

A escrita dos delírios funciona como recurso para a localização do gozo. Esse elemento é destacado por Freud. Segundo o psicanalista, como já destacamos, o delírio não deve ser percebido como uma expressão patológica, mas antes como um processo de reconstrução que pode ser mais ou menos bem sucedida. ${ }^{1}$ Porém, cabe ressaltar o quanto a precariedade desse recurso fica à mostra na ausência de alguém que verdadeiramente acolha o seu endereçamento, como aspira Schreber em sua "carta aberta a Fleschsig" (Schreber, 1995, p. 27). Como diz Lacan (1985): "Em relação à cadeia do delírio, se assim se pode dizer, o sujeito nos parece ao mesmo tempo agente e paciente. O delírio é tanto mais sofrido por ele quanto mais ele não o organiza" (p. 247).

No seminário sobre as psicoses, Lacan reconhece em Schreber diferentes etapas de reconstrução em direção a uma atitude de consentimento progressivo. Schreber admite, pouco a pouco, que a única forma de sair da situação em que se encontra é aceitar sua transformação em mulher. Com a concepção do delírio ao longo de sua escrita, Lacan revela o caráter processual da construção delirante de Schreber.

Assim, o delírio na medida em que é escrito e publicado, constitui o instrumento inventado por Schreber para localizar a interpelação que Deus the dirige, permitindo-lhe não reduzir-se a puro objeto do gozo divino.

A partir dessas contribuições que constituem os fundamentos das contribuições da psicanálise acerca da função do processo criativo na psicose, analisaremos, na sequência, a importância da arte de Arthur Bispo do Rosário na relação com a loucura que the afligia. 
2 Esse pedido, no entanto, não foi realizado a fim de que se pudesse preservar a beleza artística do manto.

\section{Um labirinto de signos: a reconstrução de Bispo do Rosário}

Arthur Bispo do Rosário produziu e colecionou um universo de miniaturas numa cela minúscula. Conjugou esforço, tempo e acordos políticos para assegurar tantas obras que, ao entrar no quarto-forte de Bispo em fins do ano 70, o olho embaralhava. Um labirinto de signos roubava a cena. (Hidalgo, 1996, p. 114)

Pouco se sabe da história de Arthur Bispo do Rosário em época anterior à sua internação na Colônia Juliano Moreira, no Rio de Janeiro, onde morou por mais de 50 anos até a sua morte. Sabe-se que é originário de uma cidade no interior de Sergipe, Japaratuba, nascido em 1909 e descendente de escravos africanos, foi marinheiro na juventude, vindo a tornar-se empregado de uma tradicional família carioca. Também trabaIhou na Light, companhia de energia elétrica do Rio de Janeiro, entre 1925 e 1938, sendo nesta época que foi acometido por um surto psicótico delirante, às vésperas da comemoração dos festejos do Natal. Em sua crise, acreditava ter visto Cristo descendo à terra com sua corte de anjos azuis e de ter recebido deste a missão de ser portador da mensagem perante Deus no dia do Juízo Final. Deveria recriar o universo, tornandose Deus de seu mundo, para então apresentá-lo reconstruído ao Criador original (Hidalgo, 1996).

Ao ser internado em hospital psiquiátrico, foi diagnosticado como esquizofrênico paranoide. Viveu até o fim de sua vida na Colônia Juliano Moreira, onde faleceu em 1989. Foi sempre considerado como um interno produtivo e colaborador. Inicialmente, trabalhou na cozinha e, em razão de seu "bom comportamento", foi-lhe concedida autorização para sair da Colônia e regressar quando bem the conviesse. Porém, não há registro de que ele tenha saído alguma vez. Portador da missão de apresentar o mundo perante Deus, ele começou a produzir objetos com os materiais que encontrava em seu cotidiano. Sua arte baseava-se na criação de esculturas, faixas e bandeiras, quase sempre reinterpretações desses mesmos objetos, produzidos com materiais algumas vezes recolhidos do lixo.

Conforme afirmava, sua missão era a de recriar o universo, mostrando a sua percepção de mundo ao Pai. Para isso, deveria estar portando um uniforme, uma espécie de manto que ele também se dedicou a realizar. Esse manto, com o qual pediu para ser enterrado ${ }^{2}$, aproxima-se em muito dos trajes da nobreza, com suas próprias dragonas e condecorações.

Bispo mostra desde o início de sua obra uma obrigação com o seu dever. Existe método em sua produção e na escolha dos objetos mumificados com os fios de seu uniforme de interno desbotado e esse método é seguido à risca ao longo dos 50 anos de produção de sua obra e de mais de mil peças produzidas. (Morais, 1998, p. 30)

Como postula Frederico Morais (1998), Bispo do Rosário passou a produzir objetos com diversos tipos de materiais oriundos do lixo e da sucata que, após a sua descoberta, seriam classificados como arte vanguardista e comparados à obra de Marcel Duchamp. Entre os temas, destacam-se navios (tema recorrente devido à sua relação com a Marinha na juventude), estandartes, faixas de mísses e objetos domésticos.

A sua obra mais conhecida é o Manto da Apresentação, que Bispo deveria vestir no dia do Juízo Final. Com ele, Bispo pretendia marcar a passagem de Deus na Terra. Os objetos recolhidos dos restos da sociedade de consumo foram reutilizados como forma de registrar o cotidiano dos indivíduos, preparados com preocupações estéticas, onde se percebem características dos conceitos das vanguardas artísticas e das produções elaboradas a partir de 1960. (Morais, 1998, p. 187)

A partir da Psicanálise, podemos afirmar que Bispo utilizava os significantes como elemento pulsante em sua obra. Seu recurso à linguagem manipula signos e brinca com a construção 
de discursos, fragmentando a comunicação em códigos privados. Inserido em um contexto excludente, Bispo driblava a instituição a todo tempo, recusando-se a receber tratamentos médicos. Todavia, dela retirava subsídios para elaborar sua obra e, assim, mesmo sendo marginalizado e excluído, é consagrado como referência da Arte Contemporânea brasileira.

Como refere Lacan (1985, p. 106) sobre a "dissolução imaginária" do psicótico, podemos entender que o desencadeamento da crise de Bispo do Rosário produz, em compensação, uma hipertrofia da imaginação. Conforme o psicanalista, essa forma de reconstrução promovida pelo delírio, quando da emergência de manifestações psíquicas inusitadas e ameaçadoras, é produzida em função da carência de amarras simbólicas.

Entre 1985 e 1986, o médico que atendia os pacientes do Pavilhão Ulisses Viana, na Colônia Juliano Moreira, escreve sobre o Bispo:

vem mantendo a mesma conduta permanece em seu quarto, realizando diversos trabalhos manuais criados por ele. (...) calmo e orientado, vive num mundo particular, onde se julga iluminado e profetiza o fim do mundo brevemente. Está na terra para cumprir sua missão. Recusa qualquer medicamento. (Morais, 1998, p. 07)

Com tantos anos de internação, no entanto, sua vida pregressa desvanecia sob a vista grassa da Psiquiatria. Nenhum dos internos escapava a essa condição, imposta pela reclusão em uma instituição total, mas Bispo era a ovelha desgarrada de um rebanho sem rumo; sua obra seu espaço de resistência interna à homogeneização proposta à loucura. Como afirma Hidalgo (1996, p .43): "À margem da vida na Colônia, ele se ilhava num pedaço de cela e se esforçava para construir um outro mundo. Neste, Bispo era rei."

\section{Arthur Bispo do Rosário e a Arte Bruta}

Bispo já evidenciara seu talento artístico no período anterior ao início das internações psiquiátricas. Há registro da elaboração de pequenas esculturas de madeira e objetos diversos. Foi, entretanto, durante os 50 anos em que esteve internado na Colônia Juliano Moreira que produziu a grande maioria de seus trabaIhos de pintura, escultura, bordado e colagens, com utilização de materiais os mais variados possíveis. Seus trabalhos foram expostos pela primeira vez fora da Colônia em 1982, na mostra À Margem da Vida, organizada pelo crítico de arte Frederico Morais, no Museu de Arte Moderna do Rio de Janeiro.

Entre 1989 e 1993, portanto depois da sua morte, foram expostas seis mostras individuais da obra de Bispo em várias instituições culturais e museus do país, sob curadoria de Frederico Morais. Tais eventos contaram com um público de visitantes aproximado de 100 mil pessoas. A exposição inaugural, no Museu de Arte Moderna do Rio de Janeiro, foi avaliada como de absoluto sucesso, promovendo publicação de reportagens, ensaios e artigos em jornais e revistas no país. Internacionalmente, a obra de Bispo participou da mostra Viva Brasil em uma das principais instituições culturais de Estocolmo, na Suécia. Em 1995, representou o Brasil na $46^{\text {a }}$ Bienal de Veneza, reconhecidamente o principal evento de artes plásticas do mundo. A partir daí, surgiram uma série de convites para que se expusesse sua obra nos Estados Unidos, México e Espanha.

A ressonância pública de sua vida e obra impulsionaram a realização de filmes: O Prisioneiro da Passagem, realizado por Hugo Denizarte, O Bispo do Rosário por Helena Rocha e Miguel Pozdoravski (Morais, 1998, p. 04). Alguns críticos de arte e artistas se mostraram particularmente atentos para a modalidade pouco convencional de Bispo 
ao confeccionar obras sem consideração pelas convenções acadêmicas, formalismos ou enquadramento estilístico.

O pintor francês Jean Dubuffet foi um dos primeiros a se interessar pela produção artística de pacientes psiquiátricos e de outros artistas despossuídos de formação acadêmica. Denominou "Arte Bruta" a estas produções atípicas inventadas a partir somente dos impulsos do artista. Em 1949, ele colocou em questão a forma de se denominar "arte de doentes mentais" como se fosse algo distinto da arte em si (Soares, 2000).

Nessa mesma época, Arthur Bispo do Rosário seguia seu rumo, compondo sozinho, remando contra maré das incongruências da Colônia. "Não recebia o papel, a tinta e o carvão, mas desfiaria o próprio uniforme para conseguir a matéria bruta de sua arte" (Hidalgo, 1996, p. 62).

\section{Delírio e Arte}

A arte nos confronta com percursos na contramão. Assim, a potência de uma obra de arte está em nos permitir o desvio, a deriva, o encontro de um enigma que não indica o caminho, mas nos obriga ao movimento da imaginação. (Sousa \& Tessler, 2007, p. 40)

O potencial artístico de Bispo confirmou-se enfaticamente após um episódio ocorrido em 1967. De acordo com Frederico Morais, estando internado na Colônia e recluso na solitária após agredir outro interno (o que era denominado como função de "faxina" contra a rebeldia de outros pacientes), foi acometido por uma alucinação auditiva que dizia "Está na hora de você reconstruir o mundo".

Quinet (2006) caracteriza esse momento da biografia de Bispo do Rosário como sendo:

desencadeante de sua criação como sintoma. A partir daí, Bispo nega-se a sair da reclusão a qual permaneceu por sete anos, decidido a acatar a ordem recebida, usando então a arte, para retratar 'tudo o que existe no mundo no momento de sua passagem'. (p. 227)

É a partir de então que Bispo irá utilizar objetos e dejetos recolhidos no cotidiano de sua permanência na Colônia para fabricar miniaturas (utensílios domésticos, maquetes de esportes, etc.), produzir esculturas mumificadas (elaboradas com a linha azul que desfiava de seu uniforme interno), bordar painéis nos quais escrevia com agulha e linha nomes de pessoas, países, acontecimentos, acidentes geográficos.

A designação dessa forma de arte como "Arte Bruta" e a discussão acerca da chamada 'arte dos loucos', porta em si questões cruciais. A absorção cultural de formas originais e diversas de manifestações expressivas e a incorporação de modelos informais, distanciados de uma lógica linear e coerente, são aspectos em proliferação e que perpassam as mais diferentes modalidades artísticas contemporâneas (o cinema, a música, a literatura). E, se isso ocorre no nível da arte, é porque consiste em uma esfera de veiculação e retração daquilo que se vislumbra na totalidade do processo sociocultural.

A obra de Bispo do Rosário apresenta, em particular, além da originalidade de sua execução, a evocação imediata da figura de seu autor e dos alicerces biográficos de sua elaboração. Trata-se de alguém movido por delírios místicos, situado, em relação aos padrões normativos, como "à margem", conforme diriam antigos teóricos sociais. Assim, é uma obra cuja intitulação categórica a situaria nos rótulos de estigma, exclusão, marginalidade social.

E eis que a obra de Bispo desponta, nesse estágio de produção cultural pós-moderna, exercendo fascínio e admiração no público, descortinando a inadiável necessidade de redimensionamento dos valores, de inclusão, na multiplicidade de discursos, de uma ótica que abarque as alteridades. 
3 Literalmente: "que comove, emociona" (DICIONÁRIO Alemão-Português, 2009, p. 197).
Bispo do Rosário agia sob influência de vozes alucinatória que Ihe diziam o que fazer. Conforme Quinet, diferentemente da criação pela sublimação, a criação pelo sintoma implica o tratamento da Coisa (das Ding) só que, desta vez, há o esvaziamento do gozo. Daí que a forma do sujeito barrar a Coisa se dê por meio de sua arte. O sintoma é, assim, entendido como uma modalidade criacionista de o sujeito lidar com o gozo para não ser aniquilado. Esse é o caso da obra de Bispo que, com sua arte, faz um "inventário do mundo", povoando-o de objetos que condensam, despedaçam, partilham o gozo da Coisa de modo a não ser invadido por ela. Sua obra é, portanto, fruto de um intencional inventário do mundo, advindo da impossibilidade de reconstrução pela via única do delírio que, no seu caso, era constituído pela missão de representar a existência da terra junto ao Criador.

Arthur Bispo do Rosário, incitado pelas vozes, fazia arte com os objetos de seu dia a dia, criando para si próprio uma ressignificação do mundo. É preciso notar que, em nenhum momento, ele fez qualquer tipo de trabalho envolvendo santos ou imagens de cunho religioso normativo, ou que tenha produzido imagens em tela ou desenhos de qualquer tipo. A reinterpretação do mundo que realizava era-lhe absolutamente singular, pois ao fazê-lo, reinterpretava a si e ao mundo a sua volta estabilizando uma significação em seu delírio.

\section{Psicose e Criação}

A importância da arte para a construção da obra de Freud é notória em diferentes textos que trabalham tanto o tema da produção artística como os efeitos estéticos produzidos no espectador. Conforme indica Rancière (2009), a arte tem uma importância fundamental na fundação da Psicanálise: ela dá testemunho da tese freudiana do inconsciente.

Isso é perceptível em diferentes aspectos da argumentação freudiana. Seu recurso à tra- gédia de Édipo Rei, por exemplo, enquanto ficção que encena o núcleo da constituição subjetiva. Também, sua recorrência ao termo Ergreifung 3 para indicar o efeito de ser "tocado" por uma obra, ser verdadeiramente capturado por ela. Uma obra de arte seria, então, uma espécie de armadilha para o sujeito, uma captura deste que estaria, com sua dor e beleza, escondido de si mesmo: o inconsciente.

Freud, no entanto, não se dedicou a trabalhar sobre a especificidade da criação artística na psicose. Deu-nos a indicação preciosa de que nesse o inconsciente se expressa "a céu aberto", o que permitiu que muitos artistas, entre eles os surrealistas, aproximassem a loucura da criação. Devemos a Lacan o desenvolvimento das questões relativas à clínica da psicose aportando uma leitura sobre o tema da criação que não a idealize ou romantize. Em síntese, tem-se a tarefa na Psicanálise de considerar a obra do artista louco sem desmerecer seu sofrimento.

Como vimos, o sujeito psicótico é invadido por um gozo, sob a forma de sofrimento, de angústia, de despedaçamento do corpo, de vozes e outros fenômenos da ordem do insuportável. Ademais, conforme escreve Quinet (2006, p. 221), será

para lidar com esse gozo que invade e diante da ausência do significante que poderia contêlo, [que o psicótico] usará o recurso do delírio e ou da arte, sendo ambos da ordem da criação, criação sui generis, pois não passa pela ordem estabelecida da cultura que é estruturada simbolicamente segundo a ordem do pai simbólico, do Nome-do-Pai. Quando referida à arte cultural, a criação pode ser articulada ao conceito de sublimação, teorizado por Freud, como um dos destinos da pulsão sexual.

Além de ser significante da paternidade, o Nome-do-Pai sustenta o neurótico diante da vertigem e até mesmo da angústia diante da borda, do limite da cadeia simbólica. Uma vez que, conforme Lacan (1991), toda criação implica no tratamento da Coisa (das Ding), o artista tenta fazer surgir na tela, nos objetos, 
nas letras, o que resta do gozo perdido pela inscrição do significante da filiação. Esse, o Nome-do-Pai, na medida em que é inscrito no sujeito barra seu acesso à Coisa, esvaziando-a de gozo, esvaziamento que tem para o sujeito o significado da castração.

Assim, é esse gozo da Coisa, do qual o sujeito na neurose sofre de nostalgia, gozo perdido desde sempre, que o artista tenta evocar no espectador. Ao fazê-lo, ele traz à baila a temática da castração, produzindo certa suspensão. Essa situação, que deveria provocar horror, horror da castração, o artista a escamoteia (produz um velamento) com a arte, fazendo emergir a fruição estética, o prazer que a arte normalmente propicia. Assim, a arte, no sentido cultural e sustentada pelo Nome-do-Pai, se organiza em torno do vazio da Coisa, povoando esse vazio com os objetos imaginários que tanto satisfazem nossos devaneios.

Já na psicose, por não haver essa mediação, a criação, conforme indica Quinet (2006), é uma tentativa de recriar ou reconstituir o ela que falha na simbolização e que joga o sujeito no vazio da significação. O delírio busca, portanto, preencher as lacunas do discurso e restabelecer uma lógica que se quebrou (Quinet, 2006, p. 221).

Lacan, em seu seminário sobre as psicoses, escreve: "um delírio deve ser julgado em primeiro lugar como um campo de significação que organizou um certo significante" (Lacan, 1988, p. 141). É nesse sentido que o trabalho do analista na clínica da psicose não difere substancialmente da clínica da neurose: é preciso deixar o sujeito falar para que aquilo que é da ordem do real, não simbolizado, possa encontrar ali um meio de inscrição.

\section{Bengalas imaginárias}

A palavra "bengala" tem, no uso comum, o sentido de suporte e apoio. Materialmente, a bengala é um bastão, um bordão que tem a função de amparar alguém, permitindo um caminhar. Considerando o uso ou posse desse objeto por aquele que apresenta uma deficiência, a bengala pode restituir a capacidade em algum momento perdida; sua fragilidade como instrumento de apoio, no entanto, pode também sofrer os efeitos de uma ruína, fazendo sua função despencar.

Do mesmo modo, os delírios são para os psicóticos uma espécie de "bengala imaginária" que surge como meio de sustentação para o sujeito. Sustentação daquilo que se faria sentir aos pedaços, como queda e fragmentação, não fosse a significação, mesmo que frágil, que o delírio the confere. A materialidade desse delírio pode ser observada tanto na escrita das Memórias por Schreber, como a produção da "Arte Bruta" por Arthur Bispo do Rosário.

Antes da primeira crise, o psicótico encontra-se muitas vezes sustentado subjetivamente em uma relação dual, com um duplo imaginário. Por falta do significante do Nome-doPai, o psicótico encontra compensação em uma série de identificações com personagens nos quais se apoia. Lacan (1988) compara esta situação pouco estável do sujeito antes do desencadeamento psicótico a um banquinho de três pés, ao qual falta o quarto pé que the daria estabilidade.

Nem todos os tamboretes têm quatro pés. Há aqueles que ficam em pé com três. Contudo, não há como pensar que venha faltar mais um só senão a coisa vai mal. Pois bem, saibam que os pontos de apoio significantes que sustentam o mundinho dos homenzinhos solitários da multidão moderna são em número muito reduzido. É possível que de saída não haja no tamborete pés suficientes, mas que ele fique firme assim mesmo até certo momento, quando o sujeito em certa encruzilhada de sua história biográfica, é confrontado com este defeito que existe desde sempre. Para designá-lo, contentamo-nos até o presente com o termo Verwerfung. (p. 231)

O sujeito psicótico é, pois, levado a servir-se de "bengalas" imaginárias que, no entanto, não lhe dão apoio quando ele tropeça no 
buraco da significação ausente. O termo pré-psicose, expresso pelos fenômenos elementares, deve ser tomado ao pé da letra, diz Lacan, de que o sujeito chegou à beira do buraco. Dessa maneira, o que mantém o esquizofrênico estabilizado, ou pelo menos fora do surto, são as bengalas imaginárias, sustentadas no eixo narcísico, bengalas das quais ele se dispõe como uma forma de se relacionar consigo mesmo e com o mundo. Na medida em que há uma dissolução imaginária, essas bengalas não servem mais de sustentação para o sujeito. Tem-se aí, a presentificação do real e, consequentemente, o desencadeamento do surto psicótico.

É neste momento que a produção artística pode restituir ao sujeito sua significação, reconstruindo a "bengala" perdida. A função do belo de modo geral, na cultura, produz efeitos imaginários que vêm a fazer suplência nos vazios da significação. As artes, dizendo de forma muito rápida, oferecem uma imagem que responde (mesmo que não satisfaçam) a nossa ânsia de representações ideais.

Assim, as suplências, bengalas imaginárias na clínica, são marcas da diversidade dos fenômenos do acontecer psíquico. Como constatamos nessa pesquisa, para o psicótico, a rede significante é lacunar, apresentando falhas em pontos importantes de amarragem da significação. Na psicose, a foraclusão do significante do Nome-do-pai impede o deslizamento do sentido. É neste lugar que os fenômenos delirantes, alucinatórios, se produzem.

Como dissemos, a construção delirante vem instaurar uma forma de realização muito própria de reconstrução. No delírio, vamos encontrar uma construção imaginária que permite um desgarramento daquilo que por vezes se impõe como perseguidor e intolerável. Por meio de uma produção como as Memórias de Schreber e a criação artística de Arthur Bispo do Rosário, esse imaginário ganha consistência. Em alguns casos, como indica Lacan acerca da obra de James Joyce, essa forma de escrita pode até fazer às vezes do significante foracluído.

\section{Para concluir: a obra como metáfora delirante}

A natureza deu ao artista a capacidade de exprimir seus impulsos mais secretos, desconhecidos até por ele próprio, por meio do trabalho que cria; e estas obras impressionam enormemente outras pessoas estranhas ao artista e que desconhecem, elas também, a origem da emoção que sentem. (Freud, 2006, p. 218)

Pesquisar a relação entre arte e psicose é aventurar-se a penetrar em um universo denso e complexo. Na clínica psicanalítica, seja com pacientes neuróticos ou psicóticos, a realidade que nos ocupa é a realidade psíquica, aquela criada pelo próprio sujeito que está ali e que sofre. Trata-se de uma realidade cifrada e inscrita em uma rede significante que possui lacunas, vazios de significação, mais ou menos abrangentes e importantes conforme a estrutura com a qual estejamos lidando.

Como já indicamos, as criações e obras de arte são construções que podem permitir ao sujeito uma sustentação subjetiva também na neurose, mas, sobretudo, na psicose. Para Lacan (1985), trata-se de reafirmar essa concepção abordando a metáfora delirante como uma "solução elegante" para ordenar o caos significante.

No caso de Schreber, revisitado acima, os dois elementos principais do sistema delirante são sua transformação em mulher e sua relação favorecida com Deus. A metáfora delirante produzida é a significação de ser "Mulher de Deus". Assim como o Nomedo-Pai na neurose, esse significante tem função de ponto de basta. Com isso, há limitação do gozo, anteriormente avassalador. A metáfora delirante, portanto, tem função organizadora, permitindo nova ordem simbólica ali onde não estava havendo nenhuma e possibilitando a recomposição do imaginário.

Conforme indica uma importante observação de Freud (2006, p. 286): 
4 "No auge de sua doença, Schreber convenceu-se da iminência de uma grande catástrofe: fim do mundo. (...). O fim do mundo é a projeção de sua catástrofe interna: seu mundo subjetivo chegou ao fim" (Freud, 2006, p. 76).
Os delírios dos pacientes parecem-me ser equivalentes das construções que erguemos no decurso de tratamento analítico - tentativas de explicação e de cura, embora seja verdade que estas, sob as condições de uma psicose, não podem mais do que substituir o fragmento de realidade que está sendo rejeitado no presente por outro fragmento que já foi rejeitado no passado (...). Tal como nossa construção só é eficaz porque recupera um fragmento de experiência perdida, assim também o delírio deve seu poder convincente ao elemento de verdade histórico que ele insere no lugar da realidade rejeitada.

Podemos verificar que Schreber formula em sua escrita o quanto sua tarefa consistia em reparar a catástrofe que atingira seu mundo. ${ }^{4}$ Freud (2006, p. 78) escreve que por meio do delírio:

o paranóico constrói-o de novo, não mais esplêndido, é verdade, mas pelo menos de maneira a poder viver nele mais uma vez. Constrói-o com o trabalho de seus delírios. A formação delirante, que presumimos ser produto patológico, é, na realidade, uma tentativa de restabelecimento, um processo de reconstrução.

Como vimos, também Arthur Bispo do Rosário se utiliza do delírio, da missão recebida de ser portador da reconstrução do mundo perante Deus no dia do Juízo Final. Ele deveria tornarse deus de seu mundo, para então apresentálo ao Criador original. Desse modo, torna literal a forma como o homem comum vê o artista: como criador de um novo mundo.

Nas palavras da biógrafa de Bispo, Luciana Hidalgo (1996, p. 195):
Sem que algum dia tivesse saído de sua cela para visitar exposições ou folhear revistas de arte em alguma biblioteca sofisticada, Bispo fez nos anos 60 assemblanges (...) A lógica formal com que Bispo envolve seus trabalhos antecipa certos aspectos da nova cultura inglesa (...). Os textos costurados de Bispo lembram os manuscritos de Joaquim TorresGarcia, nos quais se funde palavra e imagem. (...) O manto e as demais roupas de Bispo remetem aos parangolés de Hélio Oiticica, tanto quanto sua cama-nave assemelha-se à casa-ninho de Oiticica em sua residência nova-iorquina ou Éden que ele expôs em Sussex, Inglaterra.

A obra de Arthur Bispo do Rosário vazou as fronteiras do hospício, do Rio de Janeiro, do Brasil, da Europa, e ancorou na Suécia. Por meio da arte, o inconsciente a "céu aberto" do psicótico, que escancara a falha na cadeia simbólica e na produção de significação, pode incluir os pontos de ruptura da cadeia significante, na inscrição de um novo laço do sujeito com o mundo. A criação, como procuramos demonstrar neste artigo, é a via pela qual o sujeito pode passar do singular ao coletivo. Isso vale tanto para o sujeito em sofrimento como para a própria teoria psicanalítica, que, por meio de seus conceitos, busca circunscrever a particularidade de cada trabalho de transferência.

Podemos dizer, por fim, que, para criar, é preciso deixar aparecer a sede que cada um tem de se apresentar ou representar. Não para preenchê-la, mas deixar que surja, que se faça a busca do que falta a dizer. Sempre, ainda, mais. Como vimos, a leitura da clínica passeia pela escrita da cultura. 


\section{Maria Cristina Poli}

Doutora em Psicologia pela Universite de Paris, França. Docente da Universidade Federal do Rio de Janeiro, Rio de Janeiro - RJ. Brasil

E-mail: mcrispoli@terra.com.br

\section{Dalva Botelho Gandra Mesquita}

Graduação em Psicologia pela Universidade Veiga de Almeida, Rio de Janeiro - RJ. Brasil E-mail: dalvagandra@yahoo.com.br

\section{Endereço para envio de correspondência:}

Rua Pasteur, 250 - Fundos. Praia Vermelha. CEP 22290-240. Rio de Janeiro, RJ. Brasil

Recebido 14/05/2013, Aprovado 12/12/2013. 
Referências
Chiantaretto, Jean-François. (1999). L'écriture de cas chez Freud. Paris: Anthropos/Econômica.

Freud, S. (2006). Delírios e Sonhos na Gradiva de Jensen. In Edição Standard Brasileira das Obras Psicológicas Completas de Sigmund Freud. (Vol. 9. 2a ed.). Rio de Janeiro: Imago. (Trabalho original publicado em 1907).

Freud, S. (2006). Leonardo da Vinci e uma Lembrança de sua Infância. In Edição Standard Brasileira das Obras Psicológicas Completas de Sigmund Freud. Vol. 11, 2a. ed.). Rio de Janeiro: Imago. (Trabalho original publicado em 1910).

Freud, S. (2006). Notas psicanalíticas sobre um relato autobiográfico de um caso de paranóia (demência paranoides). In Edição Standard Brasileira das Obras Psicológicas Completas de Sigmund Freud. (Vol. 12. 2a ed.). Rio de Janeiro: Imago. (Trabalho original publicado em 1911)

Freud, S. (2006). Moisés e o Monoteísmo. In Edição Standard Brasileira das Obras Psicológicas Completas de Sigmund Freud. (Vol. 23, 2a ed.). Rio de Janeiro: Imago. (Trabalho original publicado em 1939).

Freud, S. (2006). A perda da realidade na neurose e na psicose. In Edição Standard Brasileira das Obras Psicológicas Completasde Sigmund Freud. (Vol. 9, 2a ed.). Rio de Janeiro: Imago. (Trabalho original publicado em 1924).

Freud, S. (2006). Neurose e psicose. In Edição Standard Brasileira das Obras Psicológicas Completas de Sigmund Freud. (Vol. 9, 2a ed.). Rio de Janeiro: Imago. (Trabalho original publicado em 1924).

Hidalgo, L. (1996). O Senhor do Labirinto. Rio de Janeiro. Ed. Rocco.
Lacan, J. (1985). O seminário, livro 03: As psicoses. Rio de Janeiro: Jorge Zahar Editor.

Lacan, J. (1991). O seminário, livro 07: A ética da psicanálise. Rio de Janeiro: Jorge Zahar Editor.

Lacan, J. (2007) O seminário, livro 23: O sinthoma. Rio de Janeiro: Zahar.

Morais, F. (1998). Uma biografia em curso. Catálogo da exposição Registro de minha passagem pela terra, Belo Horizonte.

Oliveira, R. A. S. (2010). A Invenção do Corpo nas Psicoses. São Paulo. Biblioteca Edição.

Porge, Erik. (2007). Transmitir la clínica psicoanalítica. Buenos Aires: Nueva Visión.

Quinet, Antonio. (2006). Teoria e clínica da psicose. Rio de Janeiro: Ed. Forense Universitária.

Rancière, Jacques. (2009). O inconsciente estético. São Paulo: Editora 34.

Schreber, D. P. (1995). Memórias de um Doente dos Nervos. Rio de Janeiro, Graal.

Sousa, E., \& Tessler, E. (2007). Imagens perfuradas. In Coutinho, F. et al. (Org.), A vida ao rés-dochão: artes de Bispo do Rosário. Rio de Janeiro: 7letras.

Soares, I. A. (2000). Arthur Bispo do Rosário a arte bruta e a propagação na cultura pós-moderna. Psicologia: ciência e profissão. 20(4), 38-45. doi: 10.1590/S1414-98932000000400005 